\title{
Palaeoethnobotanical Data from the High Mountainous Early Bronze Age Settlement of Tsaghkasar-1 (Mt. Aragats, Armenia)
}

\author{
Roman Hovsepyan
}

Author Address: Institute of Archaeology and Ethnography NAS RA, 15 Charents St., 0025, Yerevan, Armenia roman.hovsepyan@yahoo.com

Received: May $14^{\text {th }} 2011$

Volume: 2:58-62

Published: September $19^{\text {th }} 2011$

(C) 2011 Society of Ethnobiology

\begin{abstract}
Palaeoethnobotanical investigations suggest that at least part of the Early Bronze Age population of Tsaghkasar was settled and practiced agriculture in the high mountainous zone. People there appear to have cultivated hexa- and tetraploid wheats (probably bread wheat and emmer) and barley (possibly hulled). Bronze Age agriculture in the Southern Caucasus differs from earlier and later period when cultivation of pulses, oil-producing plants, and other plants was common. This emphasis on the cultivation and use of certain cereal grains at Early Bronze sites such as Tsaghkasar can tentatively be added to a constellation of practices associated with the Kura-Araxes culture in the South Caucasus.
\end{abstract}

Key Words: palaeoethnobotany, mountainous, Bronze Age, South Caucasus

\section{Introduction}

The high elevation Early Bronze Age (EBA) settlement of Tsaghkasar-1 was situated on the slopes of Mt. Tsaghkasar (a peak on the western flank of the massif of Aragats), at an altitude of 2080 meters above sea level (N 40 $28^{\prime}$ '31', E $43^{\circ}$ 55' 42'). The settlement belonged to the Kura-Araxes culture and dated to the last quarter of the 4th millennium BC. The settlement is comparably large, consisting of stone built structures occupying more than 10 hectares (Avetisyan 2009).

Several storage pits and many agriculture-related tools, e.g. obsidian sickles, a bronze sickle, grinding stones, hand stones, have been excavated at the Tsaghkasar-1 Early Bronze Age settlement. The discovery of tools for harvesting and processing cereals in conjunction with storage pits supports supposition regarding the practice of local agriculture in the high mountainous zone of Tsaghkasar during the Early Bronze Age.

This paper summarizes the results of a study with the primary aim of investigating the plant economy of the Early Bronze Age population of Tsaghkasar-1 settlement in the context of the vegetation cover of the settlement's microregion. This investigation represents a new and significant synthesis of archaeobotanical and excavation methodologies in the exploration of Early Bronze Age agriculture in the Mount Aragats region.

\section{Materials and Methods}

Strategic sampling of archaeological sediments was undertaken to target archaeological contexts where deposition and preservation of plant remains was most probable. Soil samples were collected from internal and external parts of buildings (in close association with walls) and from the soil contents of pits. Eight (8) soil samples with a total volume of 510 liters were recovered and processed during the 2005 and 2008 excavation seasons. Volumes of samples ranged from 10 to 60 liters, and averaged 30 liters. Processing of samples was done in two stages to isolate as many ancient plant remains as possible. First, the samples were floated ( $0.25 \mathrm{~mm}$ mesh) to separate light fraction; most of the charred remains and some mineralized materials were recovered in this fraction. After flotation the heavy fraction was wet-sieved (1 $\mathrm{mm}$ mesh); rare charred specimens and the essential part of the mineralized remains were recovered in this fraction.

The state of preservation of plant remains is relatively low at Tsaghkasar-1; more than 136 carbonized or mineralized carpological specimens were recovered (the quantity of fragments of charred cereal grains are measured in milliliters $(\sim 2.7 \mathrm{ml})$ and are not included in the 136 units or in calculations of density; Supplementary Table). The density of carpological material ranges from 0 (i.e. empty samples) to 1.7 units per 1 liter sediment, with the average result being 0.17 


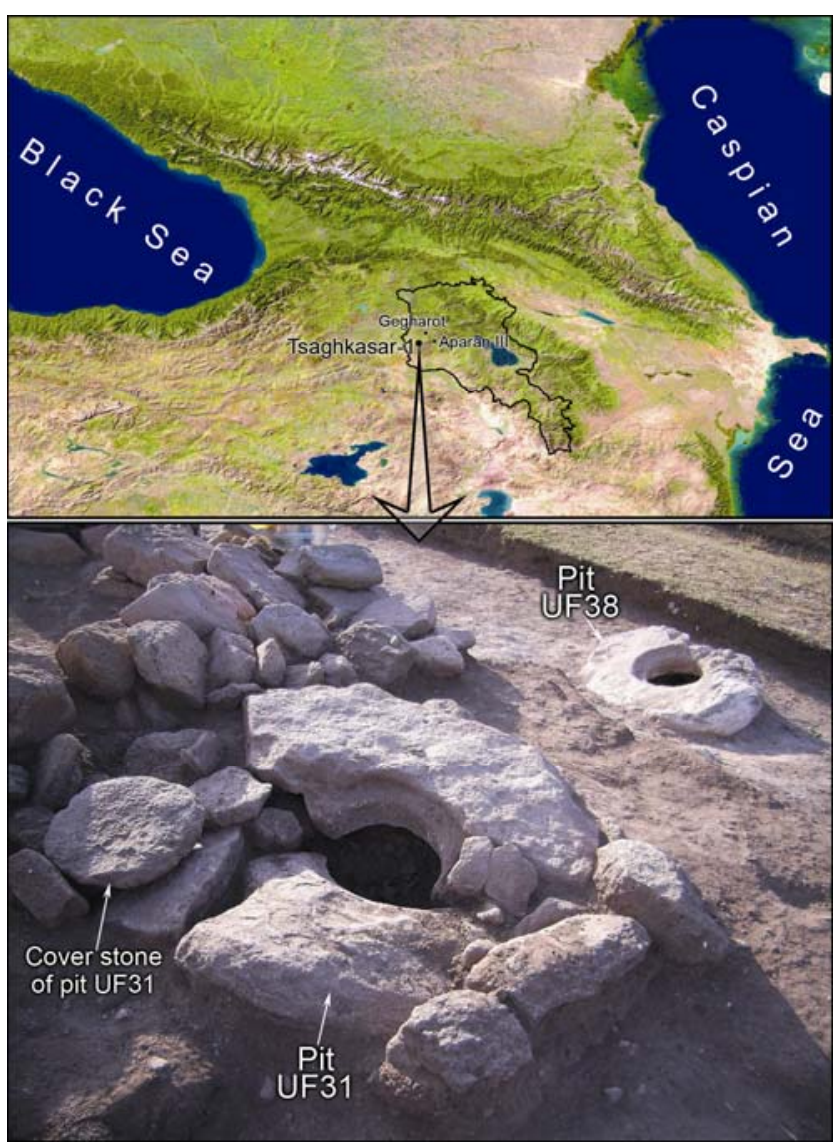

Figure 1. Location of the Early Bronze Age Tsaghkasar-1 settlement (Mt. Aragats, Armenia) and pits excavated at the site.

units/liter (Supplementary Table). To supply a modern reference dataset for identification of the archaeobotanical materials, living cultivated and weedy plants were also collected from the vicinity of the Tsaghkasar1 site.

\section{Results and Discussion}

The majority of the Tsaghkasar-1 carpological material comes from two excavated pit features (UF31 \& UF38; Figures 1 and 2; Supplementary Table). Pit UF31 was approximately $2.0 \mathrm{~m}$ deep and pit UF38 was $1.5 \mathrm{~m}$ deep. Relatively high concentration of carpological materials in soil from the lower parts of pits (Supplementary Table) suggests that archaeobotanical materials were in situ at those levels. Meanwhile, poorly preserved archaeobotanical material retrieved from other contexts, such as internal and external sides of buildings, suggests incidental deposition of material in these locations.

Identifiable cereal grains and other parts of the cereal spike are the only examples of cultivated plants at the site and consist of $56 \%$ of the identifiable carpological materials. In addition, there are also hundreds of unidentifiable fragments of cereal grains, with a total volume of $2.7 \mathrm{ml}$ that could not be identified to the genus level (Supplementary Table). The cereal grains and grain fragments are charred and are preserved well enough to be identified as cultivated wheat (Triticum) and barley (Hordeum; Poaceae).

Distinguishing between tetra- and hexaploid species of wheat based on charred grains is problematic, especially due to several kinds of distortions and deformations that result from charring. Charred wheat grains found in the Tsaghkasar-1 Early Bronze Age settlement belonged to tetra- or hexaploid species, although their morphology is closer to bread wheat, Triticum cf. aestivum s.l. (Figure 2, 1-4). The remains of other parts of the wheat spike (e.g. rachis internodes and spikelet bases) are more informative and helpful for identification. The presence of naked (free-threshing) tetra- or hexaploid wheat (Triticum aestivum/turgidum) is confirmed by the remains of rachis internodes (Supplementary Table). Several remains of spikelet bases suggest the presence of hulled wheat(s) (Triticum sp.1; Figure 2, 6). It is possible that the spikelet bases grouped under Triticum sp.1 belong to emmer (Triticum turgidum L. subsp. dicoccum (Schrank ex Schübl.) Thell. $=$ Triticum dicoccum Schrank ex Schübler). One well-preserved specimen of a hexaploid wheat rachis internode confirms the presence of Triticum aestivum s.l. (Figure 2, 5). At least some (comparably well-preserved examples) of the identified cultivated barley (Hordeum vulgare L.; Figure 2, 7-8) grains belong to a hulled variety (or varieties).

All samples from the Tsaghkasar-1 site contain charcoal fragments and coprolites of small rodents, which are indirect indicators of large-scale grain storage (Willcox et al. 2007). The presence of cereal chaff remains from storage pits may serve as additional evidence of local agriculture. The presence of hulled barley and bread wheat in the archaeological samples is also interesting from a diachronic ecological perspective; present populations of the modern Tsaghkasar village and neighboring settlements at equivalent altitude (approx. $2000 \mathrm{~m}$ a.s.l.) cultivate hulled barley and bread wheat.

Published and available palaeoethnobotanical data from Early Bronze Age archaeological sites in Armenia and parts of the Southern Caucasus (Lisitsina \& Prishchepenko 1977; Hovsepyan 2009b; Wasylikowa et al. 1991) suggest that two-rowed and six-rowed hulled barleys, common and club bread wheats, and emmer were the main field-crops cultivated in the region. This 


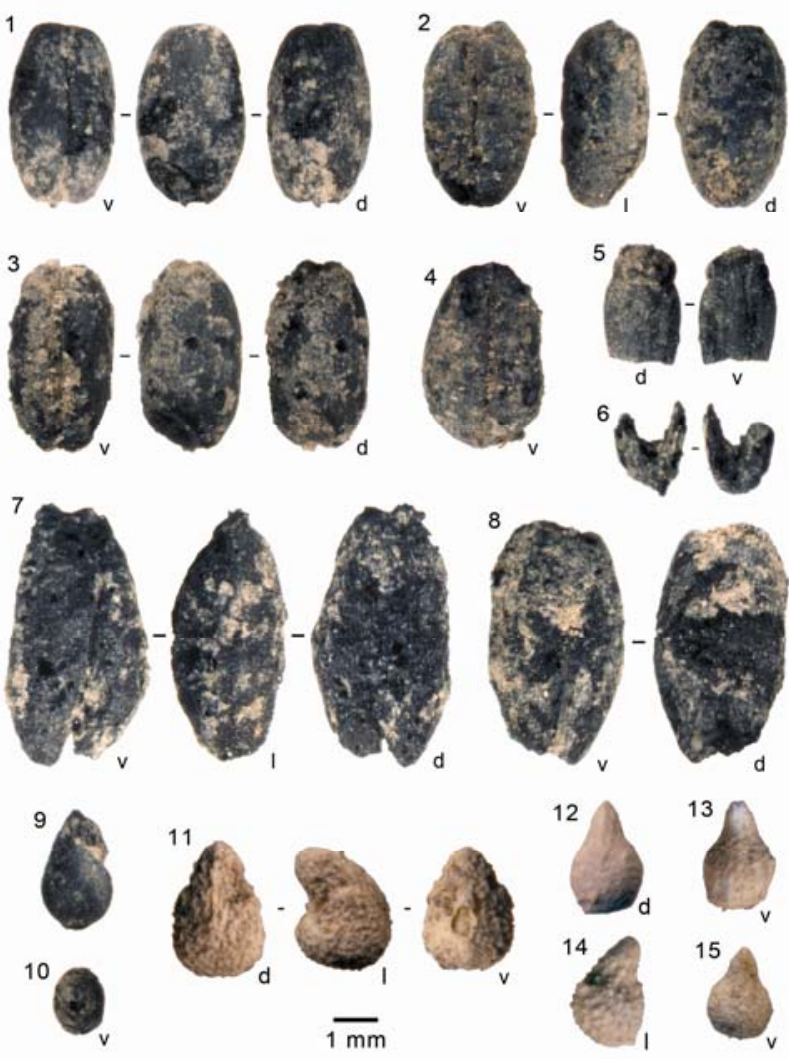

Figure 2. Carpological remains from the Early Bronze Age settlement of Tsaghkasar-1 (Mt. Aragats, Armenia). 1-4 Triticum cf. aestivum, charred kernels; 5 - Triticum aestivum s.l., charred rachis internode; 6 - Triticum sp.1 (hulled), charred spikelet fork; 7-8 - Hordeum vulgare, charred kernels, 9 - Polygonum sp., charred nutlet; 10 Galium sp., charred half mericarp; 11 - Alkanna orientalis, biomineralized erema; 12-15 - Buglossoides arvensis, biomineralized eremas. Notes: $v$ - ventral side, I - lateral side, $d$ - dorsal side.

pattern continued in the Middle and Late Bronze Ages and the Early Iron Age (the period from the second half of the 4th to the beginning of the 1 st millennium cal. BC), while in earlier (Neolithic and Chalcolithic) and later (Middle Iron Age and after) periods pulses, oil-producing plants and other field-crops (e.g. millets for Iron Age) also were common (Hovsepyan 2010b). The specialized agriculture during the Early Bronze Age in the Southern Caucasus may have been influenced by the agricultural traditions of the pre- and early Kura-Araxes culture. It is likely that these groups lived in high montane territories and practiced specialized cereal cultivation to-some-degree influenced by severe natural conditions. During the subsequent expansion of the Kura-Araxes culture, agricultural traditions spread in tandem with material culture to conquered populations. This reconstruction is derived from many ethnographic examples in which strategically situated groups continue their traditional practices and oblige local populations to assimilate their own traditions (including agriculture) in new territories.

Weedy plants recovered from Tsaghkasar-1 site are common in the modern flora of the study area and from prehistoric sites in Armenia (Supplementary Table; Hovsepyan 2009b). For example, the biomineralized erems of Buglossiodes arvensis (Boraginaceae; Supplementary Table; Fig. 2, 12-15) are present in practically all archaeological sites in Armenia. On the other hand, a single biomineralized nutlet of Alkanna orientalis (Fig. 2, 11; Boraginaceae) at Tsaghkasar-1 is the only archaeobotanical find of this genus in the territory of Armenia (though it still grows at the site). Species of Rumex, Polygonum (Polygonaceae), Poaceae, Fabaceae (wild taxa), Galium (Rubiaceae), Chenopodium (Chenopodiaceae), Scleranthus (Caryophyllaceae), Cyperaceae, Malvaceae, the seeds of which were recovered in a charred state (Polygonum: Fig. 2, 9; Galium: Fig. 2, 10), also are still growing near the site. The discovery of Scleranthus cf. annuus (Caryophyllaceae) fruit at Tsaghkasar-1 is remarkable, as it is rare in the archaeobotanical record. Despite its rarity; palaeobotanical finds of $S$. annuus were also recorded from a high mountain peat-bog (near Geghadzor, $2300 \mathrm{~m}$ a.s.l.) on the northern slope of Mt. Aragats (Hovsepyan and Gabrielyan 2002). Scleranthus was also recorded (some charred fruits were found) from the Early and Late Bronze Age layers of the high elevation settlement of Gegharot and from Late Bronze Age layers at Tsaghkahovit. Finds of these wild plants help to clarify botanical aspects of the paleoenvironmental conditions of the Aragats region during the Bronze Age.

The assemblage of cultivated plants at Tsaghkasar1 Early Bronze Age settlement is similar to corresponding datasets from the contemporary settlements of Gegharot and Aparan-III (Hovsepyan 2009a, 2010a) in the same region, where inhabitants cultivated and consumed hulled barley, bread wheat and emmer. The site of Gegharot is situated north of Mt. Aragats, at the northern boundary of the Tsaghkahovit plain, at an elevation of $2100 \mathrm{~m}$ above sea level (Hovsepyan 2009a; Fig. 1), and site of Aparan-III is situated east of Mt. Aragats in the plain of Aparan on the right bank of Kasakh River, at $1860 \mathrm{~m}$ above sea level (Hovsepyan, 2010a; Fig. 1). Linear distances between Tsaghkasar-1 and these con-temporary sites are only $40-45 \mathrm{~km}$, though the extreme topography makes effective distances somewhat greater. Carpo-logical remains belonging to Buglossoides arvensis, species of Rumex, 
Polygonum, Galium, Chenopodium and the Poaceae, Fabaceae, Cyperaceae families are also recovered from the Early Bronze Age settlements of Gegharot and Aparan-III (Hovsepyan 2009a, 2010a). Unfortunately, poorer preservation and the relative scarcity of recovered plant remains at Tsaghkasar-1 do not allow more detailed comparison between these sites.

\section{Conclusions}

Palaeoethnobotanical investigations suggest that, in the Early Bronze Age, at least some of the inhabitants of the high mountain Tsaghkasar-1 settlement were settled and practiced agriculture based on the cultivation of tetra- and hexaploid wheats and barley. It appears that environmental conditions near the site in the Early Bronze Age were similar to present: cultivated plants and weeds recorded for the Early Bronze Age period of Tsaghkasar grow there at present and there is not any evidence of environmental change. Archaeobotanical data from Tsaghkasar-1, in conjunction with data from other sites of the region, confirm that Bronze Age people of Southern Caucasus practiced agriculture specialized in the cultivation of cereals. The Bronze Age agriculture in Southern Caucasus differs from earlier, Neolithic and Chalcolithic, and later, Iron Age, agricultures, when cultivation of pulses, oil-producing plants, and other plants was common (Hovsepyan 2010b). This emphasis on the cultivation and use of certain cereal grains at Early Bronze sites like Tsaghkasar can tentatively be added to a constellation of practices associated with the Kura-Araxes culture in the South Caucasus.

\section{Acknowledgements}

The author is thankful to Pavel Avetisyan (Inst. of Archeology and Ethnography NAS RA), director of the Tsaghkasar-1 excavations, for help in organizing fieldwork and for providing necessary information about archaeological contexts. The author thanks the anonymous reviewers for their helpful comments and constructive criticism of an earlier version of the paper as well as the EBL editors for assistance with the paper.

\section{References Cited}

Avetisyan, P. 2009. Report of 2008 excavation season of

Tsaghkasar-1 Early Bronze Age settlement. Reports of archaeological field-work (2008) of Institute of Archaeology and Ethnography NAS RA, Part 1, Yerevan, pp. 189-194 (in Armenian).

Hovsepyan, R. and I. G. Gabrielyan. 2002. Palaeocarpological Finds from High Mountainous Peat-bog of Mt. Aragats (Republic of Armenia). Ecological Journal of Armenia 2:17-22 (in Armenian).
Hovsepyan, R. and G. Willcox 2008. The Earliest Finds of Cultivated Plants in Armenia: Evidence from Charred Remains and Crop Processing Residues in Pisé from the Neolithic Settlements of Aratashen and Aknashen. Vegetation History and Archaeobotany 17:63-71.

Hovsepyan, R. 2009. The palaeobotanical remains from Early Bronze Age Gegharot (Appendix 2). In: Badalyan, R., A. T. Smith, I. Lindsay, L. Khatchadourian, P. Avetisyan, with appendices by B. Monahan and R. Hovsepyan. 2009. Village, Fortress, and Town in Bronze and Iron Age Southern Caucasia: A preliminary report on the 2003-2006 investigations of Project ArAGATS on the Tsaghkahovit Plain, Republic of Armenia. ArchäologischeMitteilungen aus Iran und Turan 40:45-105.

Hovsepyan, R. 2009. Field Crops and Common Weeds at the Territory of Armenia in Neolithic - Iron Age Periods. Unpublished Doctoral Dissertation, Department of Agriculture, Armenian State Agrarian University, Yerevan (in Armenian).

Hovsepyan, R. 2010. New Data on Agriculture of Aparan-III Early Bronze Age Settlement (Armenia). Biological Journal of Armenia 4:31-37.

Hovsepyan, R. 2010. Preliminary Data on the Prehistoric Agriculture of the Southern Caucasus (The Main Phases of Development). Paper Presented at the 15th Conference of the International Work Group for Palaeoethnobotany. Wilhelmshaven, Germany (www.nihk.de).

Lisitsina, G. N. and L. V. Prishchepenko. 1977. Palaeoethnobotanical finds of Caucasus and Near East. Nauka, Moscow (in Russian).

Wasylikowa, K., M. Carciumaru, E. Hajnalova, B. P. Hartyanyi, G. A. Pashevich and Z. V. Yanushevich. 1991. East-Central Europe. In Progress in Old World Palaeoethnobotany, edited by W. van Zeist, K. Wasylikowa and K.-E. Behre, pp. 207-239. Balkema, Rotterdam, Brookfield.

Willcox, G., S. Fornite and L. Herveux. 2008. Early Holocene Cultivation before Domestication in Northern Syria. Vegetation History and Archaeobotany 17:313-325.

\footnotetext{
Biosketch

Roman Hovsepyan is an archaeobotanist (PhD Biology), who is a Research Scientist at the Institute of Archaeology and Ethnography NAS, Armenia. He is Fulbright Visiting Scholar at the Department of Anthropology, Ohio State University where he is doing research on Bronze Age agriculture of the South Caucasus.
} 
Supplementary Table. Carpological material from the Early Bronze Age period Tsaghkasar-1 settlement (from excavations in 2005 \& 2008).

\begin{tabular}{|c|c|c|c|c|c|c|c|c|c|c|}
\hline \multicolumn{3}{|l|}{ Trench / UF } & \multirow{2}{*}{\begin{tabular}{|c|}
$1 / 2$ \\
Building \\
(Str.1)
\end{tabular}} & \multirow{2}{*}{\begin{tabular}{|c|}
$3 / 2$ \\
Building \\
(Str.1)
\end{tabular}} & \multirow{2}{*}{\begin{tabular}{r|}
$3 / 35$ \\
-
\end{tabular}} & \multirow[t]{2}{*}{$3 / 37$} & \multicolumn{2}{|c|}{$3 / 38$} & \multicolumn{2}{|c|}{$3 / 31$} \\
\hline Context & & & & & & & \multicolumn{2}{|c|}{ Pit } & \multicolumn{2}{|c|}{ Pit } \\
\hline \multicolumn{3}{|l|}{ Depth of samples, $\mathrm{cm}$} & - & - & - & 338 & $80-90$ & $130-140$ & $80-90$ & $200-210$ \\
\hline \multicolumn{2}{|l|}{ Sample volume, liter } & 520 & 165 & 75 & 30 & 80 & 50 & 50 & 10 & 60 \\
\hline \multicolumn{2}{|c|}{ Concentration of carpological finds, per 10 liter sediment* } & 2.62 & 0,3 & 0,1 & 1,0 & 0,0 & 1,2 & 17,0 & 2,0 & 5,7 \\
\hline Plant taxa & Finds & 136 & 5 & 1 & 3 & 0 & 6 & 85 & 2 & 34 \\
\hline \multicolumn{11}{|l|}{ Cultivated plants } \\
\hline Triticeae spp. & grains fragments $(\sim, \mathrm{ml})$ & 2,7 & 0,5 & 0,1 & - & - & 0,5 & 1,0 & 0,1 & 0,5 \\
\hline \multirow{2}{*}{ Triticum sp. } & \multirow{2}{*}{\begin{tabular}{|l|} 
grains \\
internodes fragments
\end{tabular}} & 11 & - & - & - & - & 1 & 4 & - & 6 \\
\hline & & 3 & - & - & - & - & - & 3 & - & - \\
\hline Triticum sp.1 (hulled) & spikelet bases & 4 & - & - & - & - & - & 4 & - & - \\
\hline Triticum cf. aestivum s.l. & grains & 19 & 1 & 1 & - & - & - & 17 & - & - \\
\hline Triticum turgidum/aestivum (naked) & internodes fragments & 16 & - & - & - & - & - & 14 & 1 & 1 \\
\hline Triticum aestivum L. (naked) & internode & 1 & - & - & - & - & - & 1 & - & - \\
\hline Hordeum vulgare $\mathrm{L}$. & grains & 22 & 1 & - & - & - & 1 & 14 & - & 6 \\
\hline \multicolumn{11}{|l|}{ Weedy and wild plants } \\
\hline $\begin{array}{l}\text { Buglossoides arvensis (L.) Johnst. } \\
\text { (= Lithospermum arvense L.)** }\end{array}$ & erems & 13 & - & - & - & - & 1 & 10 & - & 2 \\
\hline Alkanna orientalis (L.) Boiss.** & erem & 1 & - & - & - & - & - & 1 & - & - \\
\hline Rumex sp. & nutlets & 8 & - & - & - & - & - & - & - & 8 \\
\hline Polygonum sp. & nutlet & 1 & - & - & - & - & - & - & - & 1 \\
\hline Poaceae sp. (wild species) & grains fragments & 5 & - & - & - & - & - & 4 & - & 1 \\
\hline Galium sp. & half mericarps & 2 & - & - & - & - & - & - & 1 & 1 \\
\hline Scleranthus cf. annuus L. & fruit & 1 & 1 & - & - & - & - & - & - & - \\
\hline Chenopodium sp. & seeds & 5 & 2 & - & - & - & - & 2 & - & 1 \\
\hline Fabaceae sp. (wild species) & seed & 1 & - & - & 1 & - & - & - & - & - \\
\hline Cyperaceae sp. & nutlet & 1 & - & - & - & - & - & - & - & 1 \\
\hline Malvaceae sp. & seed & 1 & - & - & - & - & - & - & - & 1 \\
\hline Unidentified species & seeds & 21 & - & - & 2 & - & 3 & 11 & - & 5 \\
\hline
\end{tabular}

Notes: * - Triticeae spp. grains fragments are not included in calculations

** - finds of Boraginaceae taxa are biomineralized, others are charred. 